\title{
Intracerebral hemorrhage for the palliative care provider: what you need to know.
}

\author{
B Brent Simmons \\ Section of Geriatric Medicine, Temple University School of Medicine \\ Susan M Parks \\ Division of Geriatric Medicine, Thomas Jefferson University
}

Follow this and additional works at: https://jdc.jefferson.edu/fmfp

Part of the Family Medicine Commons, Geriatrics Commons, and the Translational Medical Research Commons

\section{Let us know how access to this document benefits you}

\section{Recommended Citation}

Simmons, B Brent and Parks, Susan M, "Intracerebral hemorrhage for the palliative care provider: what you need to know." (2008). Department of Family \& Community Medicine Faculty Papers. Paper 27.

https://jdc.jefferson.edu/fmfp/27

This Article is brought to you for free and open access by the Jefferson Digital Commons. The Jefferson Digital Commons is a service of Thomas Jefferson University's Center for Teaching and Learning (CTL). The Commons is a showcase for Jefferson books and journals, peer-reviewed scholarly publications, unique historical collections from the University archives, and teaching tools. The Jefferson Digital Commons allows researchers and interested readers anywhere in the world to learn about and keep up to date with Jefferson scholarship. This article has been accepted for inclusion in Department of Family \& Community Medicine Faculty Papers by an authorized administrator of the Jefferson Digital Commons. For more information, please contact: JeffersonDigitalCommons@jefferson.edu. 


\title{
Intracerebral Hemorrhage for the Palliative Care Provider: What You Need to Know
}

\author{
B. Brent Simmons, M.D. ${ }^{1}$ and Susan M. Parks, M.D. ${ }^{2}$
}

\begin{abstract}
Intracerebral hemorrhage (ICH) makes up $10 \%-30 \%$ of all strokes. Palliative care providers are often asked to get involved with ICH cases to aid with development of short-term and long-term goals. Prognosis can be calculated using the ICH score (based on Glasgow Coma Score score, ICH volume, presence of intraventricular hemorrhage, age, and location of origin) or the Essen score (based on age, NIH Stroke Scale [NIHSS], and level of consciousness). Do-not-resuscitate (DNR) status is important to discuss with families. Expert consensus states DNR is appropriate if the patient has two of the following: severe stroke, life-threatening brain damage, or significant comorbidities. The process of withdrawing ventilatory support can differ greatly from that of a medical intensive care unit (ICU) patient. Most ICH patients die within 24 hours following extubation. Symptoms of dyspnea and pain warrant use of opioids before and after terminal extubation. In addition, treating death rattle and postextubation stridor are important interventions. Family meetings are a vital intervention to help explain prognosis, establish a plan of care, and to get all family members on the same page. Family meetings can have a rapid effect, with $66 \%$ of families opting for withdrawal of life support to decide within 24 hours of such a meeting.
\end{abstract}

\section{Introduction}

$\mathbf{I}$ NTRACEREBRAL HEMORRHAGE (ICH), a type of hemorrhagic stroke, is a common cause of severe morbidity and mortality, making up a significant proportion of all strokes. The proportion of ICH is highest in patients of Asian or African origin (30\% of all strokes), with the incidence much smaller in the white population $(10 \%-15 \%){ }^{1}$ Long-term survival varies greatly based on multiple prognostic factors. Overall, the 2 year mortality rate is $60 \%-80 \%$, with a 30 -day mortality rate of $35 \%-52 \%{ }^{2,3}$ Palliative care providers are often asked to get involved with ICH cases to aid with development of short-term and long-term goals. This includes helping the family establish goals of care, advance care planning, end-of-life issues, and often explaining the prognosis and utility of some interventions to families. The goal of this paper is to better prepare the palliative care provider to confidently treat the ICH patient and provide them with tools to better estimate prognosis in these patients.

\section{Pathophysiology}

ICH should be differentiated from other stroke types. The majority of strokes are ischemic in origin, arising from atherothrombotic or embolic causes, and will not be discussed further in this paper. There are two major types of intracranial hemorrhage: intracerebral hemorrhage (ICH) and subarachnoid hemorrhage (SAH). SAH are usually the result of a ruptured aneurysm originating in the circle of Willis. ${ }^{1} \mathrm{SAH}$ is a distinct entity from ICH, with its own prognostic scores and treatments and is beyond the scope of this paper. ${ }^{4-6}$

$\mathrm{ICH}$ arises from rupture of weakened arterial walls, which can form small outpouchings called CharcotBouchard microaneurysms. Chronic hypertension is usually the cause of this vessel weakening. Rapid increases in blood pressure can predispose to rupture, even at lower baseline levels of hypertension. ${ }^{1}$ A less common cause of ICH is ruptured vascular malformations. ${ }^{1}$ Once hemorrhage has begun, the amount of bleeding is limited due to the pressure of surrounding brain tissue. ${ }^{1}$ Larger volume hematomas and edema can lead to enough pressure to displace adjacent structures, leading to transtentorial herniation. ${ }^{1}$ This herniation is the cause of death for most patients who die during the first week after ICH. ${ }^{7}$ If patients survive the first week, the causes of death are more varied and include herniation, pneumonia, extension of hematoma, and cardiac causes. ${ }^{7}$

\footnotetext{
${ }^{1}$ Section of Geriatric Medicine, Temple University School of Medicine, Philadelphia, Pennsylvania.

${ }^{2}$ Division of Geriatric Medicine, Thomas Jefferson University, Philadelphia, Pennsylvania.
} 


\section{Treatment Guidelines}

The American Stroke Association (ASA) and American Heart Association (AHA) jointly publish extensive guidelines for the treatment of ICH. ${ }^{3}$ The only subgroup that has a clear recommendation for surgical evacuation are patients with cerebellar hemorrhage greater than $3 \mathrm{~cm}$ with neurologic deterioration, brainstem compression, or hydrocephalus. $^{3}$ Other surgical approaches for the remainder of $\mathrm{ICH}$, such as urokinase infusion into the clot cavity and minimally invasive clot evacuation, have unknown and unclear usefulness pending further clinical trials. ${ }^{3}$ Standard craniotomy "might be considered" in patients with lobar clots within $1 \mathrm{~cm}$ of the surface. ${ }^{3}$

Another section in the ASA/AHA guidelines that warrants mention is their statement on "Recommendation for Withdrawal of Technological Support." This section of the guidelines recommends full aggressive care during the first 24 hours after onset of ICH and postponing new do-not-resuscitate (DNR) orders during that time. However, they state that patients with a previous DNR order are exempt from this recommendation. ${ }^{3}$

\section{Prognosis}

In order for the palliative care provider to aid families with difficult decisions such as surgery, withdrawal of technological support, and other invasive measures such as artificial nutrition, it is important to have an estimated prognosis. Earlier prognostic formulas could predict mortality with a high level of accuracy, however, they used complex algebraic equations that could pose some difficulty in bedside calculation. ${ }^{8-11}$ Two newer models are easier to use and achieve the same level of accuracy: the ICH score and the Essen score. ${ }^{12-14}$

The first score specifically designed for rapid bedside calculation and ease of use for those not trained in neurology was Hemphill's ICH score (Table 1). ${ }^{12}$ The ICH score was designed to predict 30-day mortality following $\mathrm{ICH}$ and uses five variables to calculate life expectancy: Glasgow Coma Scale (GCS) score, ICH volume, intraventricular hemorrhage, age, and infratentorial origin of ICH. Each of the variables is assigned a score of 0,1 , or 2 . The five variables are then added up to equal the ICH score.

The original study included 152 patients. Of these, all patients with a score of 0 were alive at 30 days, and all patients with a score of 5 had died by day 30 . No patients in this study scored a 6 . For the remaining patients, scores of 1, 2, 3 , and 4 had 30 -day mortality rates of $13 \%, 26 \%, 72 \%$, and $97 \%$, respectively. ${ }^{12}$

The ICH score uses the ABC/2 method to calculate volume. If the computed tomography (CT) reading does not have the volume listed, it can be calculated using this method where $\mathrm{A}$ is the greatest hemorrhage diameter, $\mathrm{B}$ is the diameter 90 degrees perpendicular to $A$, and $C$ is the approximate number of CT slices with hemorrhage. This product is divided by 2 , and then multiplied by the slice thickness in millimeters. ${ }^{15}$ Simple to use ICH volume calculators are also available online, such as the one found at http://sitemaker. umich.edu/interact/ich_volume_calculator.

The Essen score is the latest prognostic tool to emerge, and was published for the first time in 2006 (Table 1) This score is unique in that it does not require a volume calculation and
Table 1. ICH AND EsSEN SCORES for Calculating Prognosis

\begin{tabular}{|c|c|c|c|c|}
\hline & $\begin{array}{l}\text { ICH } \\
\text { score }\end{array}$ & Points & $\begin{array}{l}\text { Essen } \\
\text { score }\end{array}$ & Points \\
\hline Age & $\begin{array}{l}\geq 80 \\
<80\end{array}$ & $\begin{array}{l}1 \\
0\end{array}$ & $\begin{array}{l}<60 \\
60-69 \\
70-79 \\
\geq 80\end{array}$ & $\begin{array}{l}0 \\
1 \\
2 \\
3\end{array}$ \\
\hline $\begin{array}{l}\text { Level of } \\
\text { consciousness }\end{array}$ & $\begin{array}{r}\text { GCS } 3-4 \\
5-12 \\
13-15\end{array}$ & $\begin{array}{l}2 \\
1 \\
0\end{array}$ & $\begin{array}{l}\text { Alert } \\
\text { Drowsy } \\
\text { Stupor } \\
\text { Coma }\end{array}$ & $\begin{array}{l}0 \\
1 \\
2 \\
3\end{array}$ \\
\hline Volume of ICH & $\begin{array}{l}\geq 30 \\
<30\end{array}$ & $\begin{array}{l}1 \\
0\end{array}$ & & \\
\hline $\begin{array}{l}\text { Intraventricular } \\
\text { hemorrhage }\end{array}$ & $\begin{array}{l}\text { Yes } \\
\text { No }\end{array}$ & $\begin{array}{l}1 \\
0\end{array}$ & & \\
\hline $\begin{array}{l}\text { Infratentorial } \\
\text { origin }\end{array}$ & $\begin{array}{l}\text { Yes } \\
\text { No }\end{array}$ & $\begin{array}{l}1 \\
0\end{array}$ & & \\
\hline NIHSS Score & & & $\begin{array}{l}0-5 \\
6-10 \\
11-15 \\
16-20 \\
\begin{array}{c}\text { Coma or } \\
\quad>20\end{array}\end{array}$ & $\begin{array}{l}0 \\
1 \\
2 \\
3 \\
4\end{array}$ \\
\hline Total & & $0-6$ & & 0-10 \\
\hline
\end{tabular}

Adapted from Hemphill JC, Bonovich DC, Besmertis L, Manley GT, Johston SC: The ICH score: A simple, reliable grading scale for intracerebral hemorrhage. Stroke 2001; 32:891-897; and Weimar C, Benemann J, Diener HC: Development and validation of the Essen intracerebral haemorrhage score. J Neuro Neurosurg Psychiatry 2006;77:601-605.

$\mathrm{ICH}$, intracerebral hemorrhage; GCS, Glasgow Coma Score; NIHSS, NIH Stroke Scale.

only uses three variables: age, NIH Stroke Scale (NIHSS) total score, and the NIHSS level of consciousness. Age and consciousness are assigned a score of 0 through 3; NIHSS is assigned a score of 0 through 4 . The three variables are then added up to equal the Essen score. ${ }^{12}$ An Essen score of greater than 7 predicts 100-day mortality with $44 \%$ sensitivity and a $95 \%$ specificity. A score less than 3 predicts complete recovery with $85 \%$ sensitivity and $86 \%$ specificity.

The sensitivity of the ICH score has been reported to be as high as $79 \%$ for predicting mortality when the score is 3 or greater with specificity around $90 \% .{ }^{14}$ This sensitivity is considerably better than the Essen score, however, Essen has superior specificity and is a good alternative to the ICH score if radiologic data is missing or difficult to retrieve.

\section{Practical Aspects of Care and End-of-Life Decision-Making}

\section{DNR orders}

In 1996, DNR recommendations were published from a consortium of 26 experts in acute stroke from New York and Canada. ${ }^{16}$ DNR was defined by this consortium as withholding cardiopulmonary resuscitation (CPR). They concluded that DNR orders are appropriate any time two of the following clinical criteria are met: 
1. Severe stroke, defined as persistent/deteriorating neurological deficit, little or no activity on at least one side of the body, and with either impaired consciousness, global aphasia, or lack of response (GCS $<9$ ).

2. Life-threatening brain damage, associated with brainstem compression, intraventricular extension, cerebellar lesions, infratentorial location involving multiple brainstem levels, or midline shift.

3. Significant comorbidities, including pneumonia, pulmonary embolism, sepsis, recent myocardial infarction, cardiomyopathy, and life-threatening arrythmias.

DNR orders are often misinterpreted by staff to act as a proxy for overall aggressiveness of care. Often it may be necessary for the palliative care provider to educate family members, nursing staff, and physicians to the fundamental difference between having a DNR and decisions regarding overall aggressiveness of care.

\section{Withdrawal of ventilatory support}

The process of withdrawing life support from an ICH patient can differ greatly from that of a medical ICU (MICU) patient. MICU patients may be on many life-sustaining interventions that can be withdrawn in a step-wise fashion and are often patients with multiple organ failure and "physiologic futility." 17 By contrast, neurologic ICU patients usually require only ventilatory support, are more often hemodynamically stable, and have a lower mortality rate compared to MICU patients. ${ }^{17,18}$ These differences can lead to longer survival times and difficulties in family decision-making.

After a consensus is reached between the health care teams and families for withdrawal of ventilatory support, terminal extubation is performed. Terminal extubation in this setting can lead to a wide range of survival time. A 1999 study of life support withdrawal in neurologic ICU patients showed $25 \%$ mortality within one hour of extubation and $69 \%$ mortality within 24 hours. The median duration of survival was 7.5 hours, with a range of 10 minutes to 11 days following extubation. ${ }^{17}$ Interestingly, the GCS score at the time of extubation had no effect on the duration of survival. ${ }^{17}$ The majority (59\%) of patients experienced agonal or labored breathing following extubation. ${ }^{17}$ Given that many $\mathrm{ICH}$ patients will be comatose, some of the palliative measures are done to ease the process of death for family members.

Opioids have been shown to decrease the work of breathing, control tachypnea, and decrease feelings of air-hunger without causing increases in transcutaneous readings of $\mathrm{PCO}_{2} \cdot{ }^{19,20}$ Pain, although uncommon in $\mathrm{ICH}$ patients, may be present and should be evaluated for if the patient is in distress. Liberal use of opioids to control dyspnea and pain is recommended, starting with a bolus of 5 to $10 \mathrm{mg}$ of morphine if signs of distress are present, and then repeat doses as often as every 10 minutes if needed. After comfort is attained through this method, a continuous infusion of $50 \%$ the loading dose per hour should be started and titrated as appropriate. ${ }^{17}$ The mean dose of morphine during this study was $6.3 \mathrm{mg} / \mathrm{hr}$ with a maximum dose of $20 \mathrm{mg} / \mathrm{hr}$, and other studies have shown the average dose of opioids as high as $18 \mathrm{mg} / \mathrm{hr}$ during the final 2 hours of life. ${ }^{17,21}$ Doses of opioids exceeding what is necessary to achieve comfort are not recommended. ${ }^{22}$
Postextubation stridor and "death rattle" are common and can be quite distressing to family members. The death rattle results from excessive bronchopulmonary secretion. One recommendation to control this phenomenon includes a twophase process. The first phase, starting 6 hours prior to extubation involves stopping enteral feedings and reducing parenteral fluids. Also at this time, furosemide can be given in cases of fluid overload, and $100 \mathrm{mg}$ methylprednisolone IV can be given to help prevent postextubation stridor. ${ }^{22}$ The second phase, carried out 30 minutes prior to extubation, involves administration of $20 \mathrm{mg}$ butylscopolamine or $0.4 \mathrm{mg}$ hyoscine hydrobromine to prevent death rattle. ${ }^{22}$

Palliative sedation is often not necessary in terminal $\mathrm{ICH}$ patients due to the extensive neurologic damage. However, if it is required for relief of intractable symptoms distressing to the patient and family despite opioid administration, sedation may be warranted. ${ }^{22}$ Propofol or benzodiazepines such as midazolam or lorazepam can be used to this effect. Finally, many facilities have their own weaning protocols, and we encourage you to inquire about such a protocol at your institution.

A common barrier to liberal narcotic use among families and health care providers is concern over hastening death through respiratory depression. Multiple studies have shown this not to be the case. A small, recent study showed opioid treatment of dyspnea to significantly decrease tachypnea, with average respiration rate dropping from 41.8 per minute prior to opioid administration to 26.5 per minute 60 minutes following dosing. Despite this impressive decrease in respiratory rate, $\mathrm{SaO}_{2}, \mathrm{PaCO}_{2}$, and pulse rate showed no significant change from baseline. ${ }^{20}$ The authors go on to state that since there was no increase in hypercapnia, opioid administration did not lead to respiratory depression despite decreased respiratory rate. ${ }^{20}$ Additionally, a 2004 study investigated narcotic use after withdrawal of mechanical ventilation in ICU patients. This study showed a steep escalation of narcotic use during the last 2 hours of life, however, no statistical association was observed between opioid use and time of death. ${ }^{21}$ There is a physiologic basis to the observation that opioids do not cause respiratory depression, and can actually lead to a small prolongation of life. It has been proposed that opioids decrease the demand for oxygen and attenuate the cardiopulmonary response to increased work of breathing, leading to a higher tolerance to decreased levels of oxygen delivery. ${ }^{19}$ These data should reassure physicians and families that they should not withhold comfort measures following terminal extubation.

\section{Family meetings}

ICH happens very suddenly and usually catches families off guard. The family meeting is a vital intervention to help explain prognosis, to formulate a plan of care most in-line with the patient's wishes, and to get all family members on the same page. The family meeting can have a rapid effect, with one study showing the interval between discussing withdrawal of life support to actual extubation to be less than 24 hours in $66 \%$ of patients. ${ }^{17}$ This same study surveyed the families of ICU patients 1 year after undergoing terminal extubation. The most important factors families used in their decision to withdraw ventilatory support included quality of life, overall prognosis, and current level of suffering. Sev- 
enty-five percent of respondents felt that the decision to withdraw life support should be made by the family and physicians together. ${ }^{17}$ The family meeting facilitates shared decision making between health care providers and families.

\section{Summary}

$\mathrm{ICH}$ is a common and often fatal condition. Because of this, palliative care providers are often consulted to aid the patient, family, and health care providers in difficult end-oflife decision-making. In order to appropriately guide these discussions, an understanding of prognosis is vital. The score calculations outlined in this article are a valuable tool; however, their limitations should be recognized. The family meeting is a key intervention for the palliative care provider to use in conjunction with the neurology and neurosurgery primary teams. If a decision is made for terminal extubation, the focus should be on comfort care and use of opioids for respiratory distress or pain and consideration can be given to anticipatory measures to prevent death rattle and postextubation stridor. Discussing DNR orders with the family is important for the palliative care provider. It should be made clear that DNR orders do not equal withdrawal of aggressive treatment. The palliative care provider can play a central role in providing care for ICU patients with ICH and their families.

\section{References}

1. Goetz CG: Hemorrhagic cerebrovascular diseases. In: Textbook of Clinical Neurology, 3rd ed. 2007 Philadelphia: Saunders, 2007.

2. Saloheimo P, Lapp TM, Juvela S, Hillborn M: The impact of functional status at three months on long-term survival after spontaneous intracerebral hemorrhage. Stroke 2006;37: 487-491.

3. Broderick J, Connolly S, Feldmann E, Hanley D, Kase C, Krieger D, Mayberg M, Morgenstern L, Ogilvy CS, Vespa P, Zuccarello M; American Heart Association; American Stroke Association Stroke Council; High Blood Pressure Research Council; Quality of Care and Outcomes in Research Interdisciplinary Working Group: Guidelines for the management of spontaneous intracerebral hemorrhage in adults 2007 update. Stroke 2007;38:2001-2023.

4. Rosengart AJ, Schultheiss KE, Tolentino J, Macdonald RL: Prognostic factors for outcome in patients with aneurismal subarachnoid hemorrhage. Stroke 2007;38:2315-2321.

5. Manno EM: Subarachnoid hemorrhage. Neurol Clin North Am 2004;22:347-366.

6. Hunt WE, Hess RM: Surgical risk as related to time of intervention in the repair of intracranial aneurysms. J Neurosurg 1968;28:14-20.

7. Silver FL, Norris JW, Lewis MB, Hachinski VC: Early mortality following stroke: A prospective review. Stroke 1984; 15:492-496.

8. Portenoy RK, Lipton RB, Berger AR, Lesser ML, Lantos G: Intracerebral haemorrhage: A model for the prediction of outcome. I Neurol Neurosurg Psychiatry 1987;50:976979.

9. Lisk DR, Pasteur W, Rhoades H, Putnam RD, Grotta JC: Early presentation of hemispheric intracerebral hemorrhage: Prediction of outcome and guidelines for treatment allocation. Neurology 1994;44:133-139.

10. Tuhrim S, Horowitz DR, Sacher M, Godbold JH: Validation and comparison of models predicting survival following intracerebral hemorrhage. Crit Care Med 1995;23:950-954.

11. Ariesen MJ, Algra A, van der Worp HB, Rinkel GJE: Applicability and relevance of models that predict short term outcome after intracerebral haemorrhage. I Neurol Neurosurg Psychiatry 2005;76:839-844.

12. Hemphill JC, Bonovich DC, Besmertis L, Manley GT, Johnston SC: The ICH score: A simple, reliable grading scale for intracerebral hemorrhage. Stroke 2001;32:891-897.

13. Weimar C, Benemann J, Diener HC: Development and validation of the Essen intracerebral haemorrhage score. J Neurol Neurosurg Psychiatry 2006;77:601-605.

14. Cheung RTF, Zou LY: Use of the original, modified, or new intracerebral hemorrhage score to predict mortality and morbidity after intracerebral hemorrhage. Stroke 2003;34: 1717-1722.

15. Kothari RU, Brott T, Broderick JP, Barsan WG, Sauerbeck LR, Zuccarello M, Khoury J: The ABCs of measuring intracerebral hemorrhage volumes. Stroke 1996;27:1304-1305.

16. Alexandrov AV, Pullicino PM, Meslin EM, Norris JW: Agreement on disease-specific criteria for do-not-resuscitate orders in acute stroke. Stroke 1996;27:232-237.

17. Mayer AM, Kossoff SB: Withdrawal of life support in the neurological intensive care unit. Neurology 1999;52: 1602-1609.

18. Keenan SP, Busche KD, Chen LM, McCarthy L, Inman KJ, Sibbald WJ: A retrospective review of a large cohort of patients undergoing the process of withholding or withdrawal of life support. Crit Care Med 1997;25:1324-1331.

19. Bakker J, Jansen TC, Lima A, Kompanje EJ: Why opioids and sedatives may prolong life rather than hasten death after ventilator withdrawal in critically ill patients. Am J Hosp Palliat Med 2008;25:152-154.

20. Clemens KE, Klaschik E: Symptomatic therapy of dyspnea with strong opioids and its effect on ventilation in palliative care patients. I Pain Symptom Manage 2007;33:473-481.

21. Chan JD, Treece PD, Engelberg RA, Crowley L, Rubenfeld GD, Steinberg KP, Curtis JR: Narcotic and benzodiazepine use after withdrawal of life support: Association with time to death? Chest 2004;126:286-293.

22. Kompanje EJ, van der Hoven B, Bakker J: Anticipation of distress after discontinuation of mechanical ventilation in the ICU at the end of life. Intensive Care Med 2008;34:1593-1599.

Address reprint requests to: B. Brent Simmons, M.D. 1316 W. Ontario Street Jones Hall

Philadelphia, PA 19140

E-mail: b.brent.simmons@tuhs.temple.edu 
This article has been cited by:

1. Robert G. Holloway, Susan Ladwig, Jessica Robb, Adam Kelly, Eric Nielsen, Timothy E. Quill . 2010. Palliative Care Consultations in Hospitalized Stroke Patients. Journal of Palliative Medicine 13:4, 407-412. [Abstract] [Full Text] [PDF] [PDF Plus] 